\title{
Giant Vascular Malformation in an Infant's Hand
}

\section{التشوه العملاق للأوعية الدموية في يد رضيع}
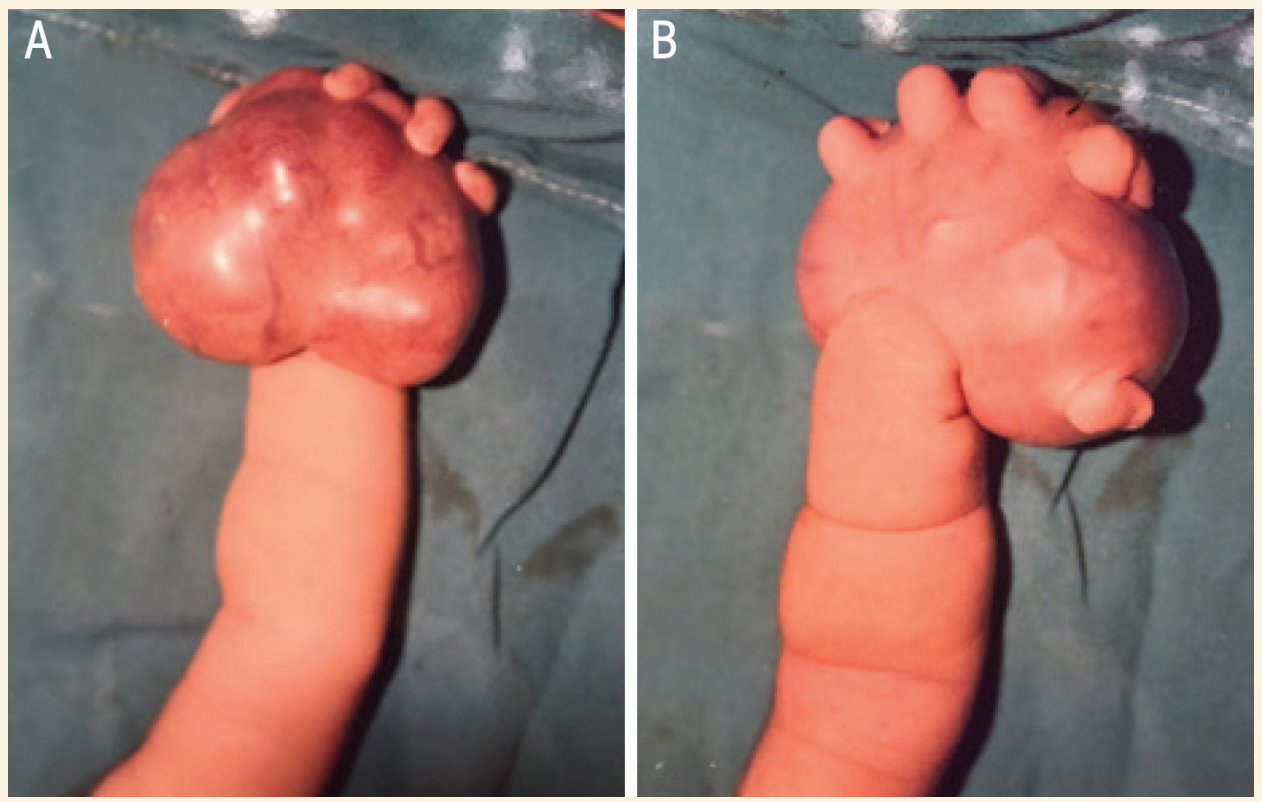

Figure 1: Photographs of the hand of a 40-day-old infant showing the (A) palmer and (B) dorsal aspect of a haemangioma.

A 40-DAY-OLD INFANT WEIGHING 3.5 KG WAS referred to the Department of Paediatric Surgery at Pandit Bhagwat Dayal Sharma Post Graduate Institute of Medical Sciences, Rohtak, Haryana, India, in 2016 with swelling of the left hand since birth. The swelling was soft, oval and approximately $9 \times 7 \mathrm{~cm}$ in size starting from the base of the hand proximally and extending up to the distal interphalangeal joints [Figure 1]. The size of swelling had progressively increased since birth. Due to the large size of the swelling, movement of the wrist joint was restricted and the hand was grossly deformed. An X-ray of the lesion revealed a soft tissue swelling with multiple calcifications. Absolute platelet count and coagulation profile were within normal ranges; abdominal ultrasound and chest X-ray were unremarkable. With the differential diagnosis of giant vascular malformation, infantile haemangioma and tufted angioma involving proximal part of all fingers, palmer and dorsal surface of the hand, further interventions were planned. However, the parents chose to discharge the infant against medical advice.

\section{Comment}

The diagnosis of vascular lesions such as infantile haemangioma, Kaposiform haemangioendothelioma (KHE), tufted angioma (TA) and vascular malformations are usually established by clinical features, radio-imaging and immunohistochemical markers. ${ }^{1}$ Benign vascular neoplasm KHE has a wider age of presentation then infantile haemangioma. Similarly, TA presents in infants, children or young adults and are usually located on the neck or the upper part of the thorax. Both, KHE and TA have glucose transporter protein isoform (GLUT1) negative endothelial cells and 
may be associated with thrombocytopaenia. Vascular malformations are congenital lesions that sometimes become apparent later in life and do not involute spontaneously. Haemangiomas are the most common benign soft tissue tumours in infants, found in 4-10\% with higher female preponderance. ${ }^{2}$ Haemangiomas are seen most commonly in the craniofacial region (60\%), followed by the trunk (25\%) and extremities (15\%). Immunohistochemical markers such as GLUT1 can be useful for differentiating haemangiomas from other vascular lesions. ${ }^{3}$ After a rapidly proliferative phase during the early infantile period, most uncomplicated lesions undergo spontaneous slow involution and an active non-intervention approach may be preferred. ${ }^{4}$ However, some children require further intervention due to associated complications.

Therapeutic interventions are based on the location, size of haemangioma, age of the patient, presence of complications and experts' and parents' preferences. Beta-blockers (e.g. oral propranolol) haveshown promising results in uncomplicated haemangiomas; however, detailed cardiovascular and respiratory evaluation is required before initiating these drugs. ${ }^{5}$ Oral propranolol therapy is usually given for 6-12 months depending on the size and location of the lesion.

In recent years, the use of corticosteroids to treat haemangiomas has decreased and is only used when beta-blockers are contraindicated. ${ }^{4}$ Other medications such as vincristine, interferon- $\alpha$ and imiquimod may be useful but are rarely used due to their serious sideeffects. Recently, the common antifungal agent itraconazole has been found to be useful in the treatment of infantile haemangioma by inhibiting proliferation and promoting apoptosis of infantile primary haemangioma endothelial cells. ${ }^{6}$
In addition to pharmacological treatment, laser therapy and surgical interventions are alternative treatment options. Although pulsed-dye laser treatment has debatable efficacy, they may be used on superficial lesions. ${ }^{7}$ Excisional surgery may be undertaken when the haemangioma causes visual or subglottic obstruction, bleeding or recurrent ulceration as well as slow involution or failure of pharmacological treatment. ${ }^{5}$

\section{References}

1. Perman MJ, Castelo-Soccio L, Jen M. Differential diagnosis of infantile hemangiomas. Pediatr Ann 2012; 41:e160-6. https://doi.org/10.3928/00904481-20120727-09.

2. Lowe LH, Marchant TC, Rivard DC, Scherbel AJ. Vascular malformations: Classification and terminology the radiologist needs to know. Semin Roentgenol 2012; 47:106-17. https://doi. org/10.1053/j.ro.2011.11.002.

3. Darrow DH, Greene AK, Mancini AJ, Nopper AJ. Diagnosis and management of infantile hemangioma: Executive summary. Pediatrics 2015; 136:786-91. https://doi.org/10.1542/peds.201 5-2482.

4. Sethuraman G, Yenamandra VK, Gupta V. Management of infantile hemangiomas: Current trends. J Cutan Aesthet Surg 2014; 7:75-85. https://doi.org/10.4103/0974-2077.138324.

5. Sepulveda A, Buchanan EP. Vascular tumors. Semin Plast Surg 2014; 28:49-57. https://doi.org/10.1055/s-0034-1376260.

6. Chen S, Zhuang K, Sun K, Yang Q, Ran X, Xu X, et al. Itraconazole induces regression of infantile hemangioma via down regulation of the platelet-derived growth factor-D/PI3K/ Akt/mTORpathway. J Invest Dermatol 2019; 139:1574-82. https://doi.org/10.1016/j.jid.2018.12.028.

7. Stier MF, Glick SA, Hirsch RJ. Laser treatment of pediatric vascular lesion: Port wine stains and hemangiomas. J Am Acad Dermatol 2008; 58:261-85. https://doi.org/10.1016/j.jaad.200 7.10.492. 